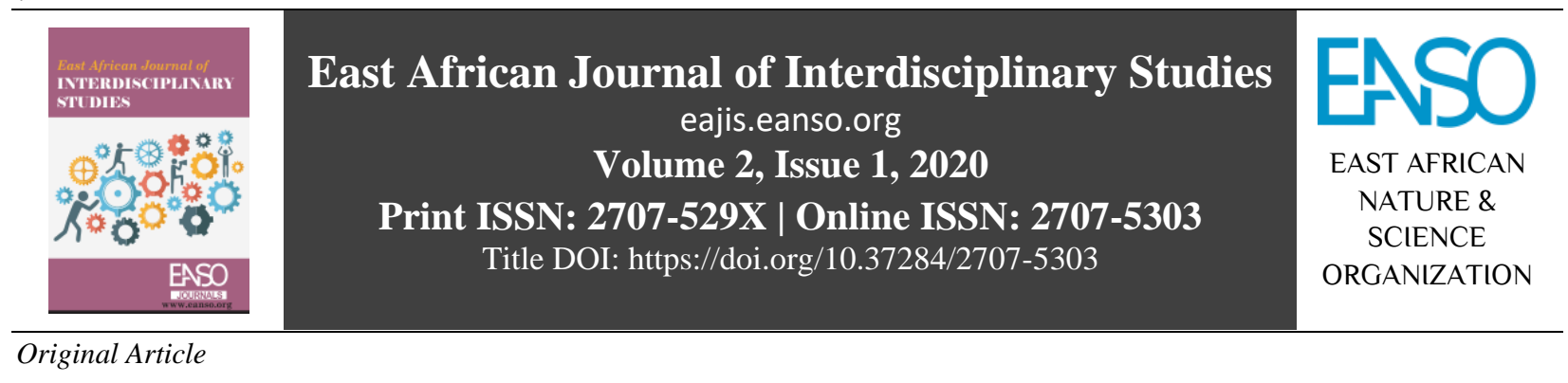

\title{
Social Strategies Used by the Kipsigis Women to Contest Patriarchal Structures as Highlighted in the Songs of Diana Chemutai Musila and Babra Chepkoech
}

\author{
Beatrice Chepkoech Mutai ${ }^{1 *}$, Christopher Okemwa, PhD ${ }^{1}$ \& Nyagemi Bwocha, PhD \\ ${ }^{1}$ Department of Literature, Kisii University, P. O. Box 408 - 40200, Kisii, Kenya. \\ *Author for Correspondence Email: beatricemutai79@gmail.com
}

Article DOI: https://doi.org/10.37284/eajis.2.1.215

Date Published: ABSTRACT

17 September 2020 Many women in Kenya, and in particular those in the Kipsigis community, are still faced with many challenges due to the patriarchal nature of their society,

Keywords:

Patriarchy,

Freedom,

Gender,

Kipsigis Songs,

Feminism. attaining gender equality. Among the many methods of protest, art has been used in many societies as an instrument for contesting social ills including patriarchy. This has also been true to the Kipsigis community. Therefore, this research aimed to investigate the use of selected popular Kipsigis songs of Diana Chemutai Musila (Chelele) and Babra Chepkoech to contest patriarchy. Specifically, the study analysed the aspects of patriarchal oppression of the Kipsigis women as depicted in the selected Kipsigis songs; explored ways used by the Kipsigis women to contest patriarchy as highlighted in the selected Kipsigis songs and examined the literary devices used by the selected singers to expose patriarchal oppression in the selected Kipsigis songs. The target population were ten songs from the two Kipsigis artists. These artists and their songs were chosen purposively. The study was guided by American feminist literary critic and writer Elaine Showalter's feminist ideas to explore how the artists capture the experiences of the Kipsigis women in their songs. Specifically, the study used theory to describe the existing tendencies of patriarchy in the Kipsigis society as depicted in the community's Kipsigis songs. The data was analysed thematically and interpreted in line with the research objectives, the reviewed literature and the theoretical framework adopted for the study. The research established that popular songs, in general, are used not only for entertainment but also to address issues of great concern for society such as fighting for equity among spouses in the Kipsigis community. The study saw that there was/is need for composers to develop music that portrays positive roles of members of both genders, which could lead to the realization of an equiponderant society where men and women coexist peacefully.

\section{APA CITATION}


Mutai, B. C.., Okemwa, C., \& Bwocha, N. (2020). Social Strategies Used by the Kipsigis Women to Contest Patriarchal Structures as Highlighted in the Songs of Diana Chemutai Musila and Babra Chepkoech. East African Journal of Interdisciplinary Studies, 2(1), 71-88. https://doi.org/10.37284/eajis.2.1.215

\section{CHICAGO CITATION}

Mutai, Beatrice Chepkoech, Christopher Okemwa, and Nyagemi Bwocha. 2020. "Social Strategies Used by the Kipsigis Women to Contest Patriarchal Structures as Highlighted in the Songs of Diana Chemutai Musila and Babra Chepkoech". East African Journal of Interdisciplinary Studies 2 (1), 71-88. https://doi.org/10.37284/eajis.2.1.215.

\section{HARVARD CITATION}

Mutai, B. C., Okemwa, C. and Bwocha, N. (2020) "Social Strategies Used by the Kipsigis Women to Contest Patriarchal Structures as Highlighted in the Songs of Diana Chemutai Musila and Babra Chepkoech", East African Journal of Interdisciplinary Studies, 2(1), pp. 71-88. doi: 10.37284/eajis.2.1.215.

\section{IEEE CITATION}

B. C. Cheruiyot, C. Okemwa, and N. Bwocha, "Social Strategies Used by the Kipsigis Women to Contest Patriarchal Structures as Highlighted in the Songs of Diana Chemutai Musila and Babra Chepkoech", EAJIS, vol. 2, no. 1, pp. 71-88, Sep. 2020.

\section{MLA CITATION}

Mutai, Beatrice Chepkoech, Christopher Okemwa, and Nyagemi Bwocha. "Social Strategies Used by the Kipsigis Women to Contest Patriarchal Structures as Highlighted in the Songs of Diana Chemutai Musila and Babra Chepkoech". East African Journal of Interdisciplinary Studies, Vol. 2, no. 1, September 2020, pp. 71-88, doi:10.37284/eajis.2.1.215.

\section{INTRODUCTION}

Popular music as an art form is highly gendered. This has proved to be a fertile ground for the display or playing of different identities, a ready-made arena for exposing these identities. As an art form, popular music also plays a significant part in the representation of gender and sexuality in contemporary social settings (Bennett, 2005). Frith and McRobbie (cited in Bennett, 2005) argued that in some cases, such representation had emphasized dominant gender roles, as in the case of rock and heavy metal songs that portray male domination and physical aspects of the body. Among the Kipsigis, both male and female singers dominate the popular music scene

Gender ideology is also relevant in the sociology of culture because it can be studied in the same manner as the racial hierarchy (Bharadwaj, 2007). According to Chenorff (1979), making songs is not a way of expressing ideas, but rather a way of living them. Messages portrayed in songs mirror the dominant and hegemonic ideas about social life and sexuality and Kipsigis songs are far from being merely a passive pleasure (Bennett, 2005). When one listens to many of the Kipsigis songs, there is evidence of attempts to both delight and instruct the audience on various issues. This realization makes this type of songs a fertile ground for exploring how artists contest aspects of patriarchal structures within the Kipsigis society.

The word patriarchy became popular in postcolonial studies. As multiple waves of feminism evolve around the globe, utilizing new technology such as social media to spread their messages. Patriarchy has become a household term in some parts of the world. Simply put, patriarchy is systemic of privileging of men merely for being men. Patriarchy is found in almost every part of the world, as are songs.

Songs touch on many different aspects of human existence. Most times they are part of ceremonies such as weddings and funerals. Other times, they are part of a person's job as a musician or director. Most times, however, songs are just part of daily life. With all of these different venues and avenues, songs can be used to serve many functions, including bringing back and reliving the memories of past events and relationships, managing emotions and constructing or reinforcing selfidentify (Dowd, 2007). Songs can be used to create and relay entire cultures, subcultures, the reproduction of inequality, globalization, identify formation, and social movements (Dowd, 2007). According to Rogers (2013), customs and beliefs of a society are often reflected in its songs. As such, a patriarchal society's songs can have effects on subcultures, people's identities and inequalities. 
Based on this view, this study investigated how the Kipsigis songs contest with structures of patriarchy and gender in the community.

Compared to their male counterparts, women worldwide have continued to face greater social discrimination across history. The subordination of women has been more pronounced in developing countries of Asia and Africa. In this context, several scholars (Kenig, 1996; Adeyeye, Ogundele, \& Hahn, 1988; Kazi, 1995; Kumar, 1993) have asserted that rural women are discriminated against in terms of employment opportunities, access to social and productive resources, education, health status and family decisions, among others. However, rural women in developing countries have been found to play an important role in agriculture and agricultural development (Kumar, 1993). Williams (1988), Mabawonku (1988) and Olawaye (1994) all have emphasized the paradox that a woman is a nutritional bedrock of human society who feeds and nurtures humanity and, yet, at the same time, the manager of the home. For instance, majority of the Kipsigis rural women engage in tea plucking businesses that ultimately improve the living standards of their families. Therefore, this study analysed the contestation of patriarchal oppression of the Kipsigis women as portrayed in the selected Kipsigis songs.

Due to the prevalence of patriarchy, the pursuit for gender equality became known as a women's issue, and, true to that fact, women have primarily been at the forefront of advancing the gender agenda. However, it is important to note that gender parity is good for both men and women, and, as such, even men can join, and have indeed joined, the struggle for equality of genders. The persistence of the women's rights campaigns since the foundation of the United Nations has resulted in the recognition of gender relations as key to the transformation of the entire humanity. Therefore, part of the objective of this research is to show how the struggle against patriarchy in the Kipsigis community as a product of concerted efforts by both men and women, as espoused in the texts under this study.

Resolving gender issues has been a topic of high importance that receive worldwide attention nowadays. The topic describes the high level of suffering African women have faced for many years. Accordingly, women are regarded as toys while men considered (in many traditional African societies) women as lacking any ability to succeed in life. As such, women were often excluded from all important social activities (Moussa, 2015). This study thus analysed how artists portray the state of women's oppression and struggle for gender parity in the selected Kipsigis songs, something that corroborated Moussa's view that men deemed women as lacking the ability to succeed in life.

This research treated the lyrics of the selected Kipsigis songs as the text to be studied. As Dowd (2007) noted, sociologists of songs have generally not paid great attention to the lyrical content of songs. Dowd hopes that more research can be done on musical content in the future in order to perhaps make a better analysis of genres. Taking a cue from Dowd's recommendations, this study closely examined the content of the selected Kipsigis songs in order to uncover issues of gender among the Kipsigis.

This study was oriented towards a literary and sociological analysis of gender. Sociologists of gender seek to explain the social phenomena were members of a society define and perform the roles around the dichotomy of masculinity and femininity. They study both gender roles as well as sex roles (Mary Anne, 1995). As a field of study, the sociology of gender confronts this notion of predestined dichotomy and questions media practices that make such differences seem natural or permanent. Literary feminists, on the other hand, work to show that biological differences between humans do not make the assumption of these roles acceptable to subordinate minorities of the population in society (Mary Anne, 1995). Gender ideology is an important area of sociology of gender because it looks at how both men and women construct their reality and identities based on beliefs that are reproduced in the media. These beliefs can justify gender status roles and the normalized levels of inequality that occurs within society (Kroska, 2007). Gender ideology is also relevant in the sociology of culture because it can be studied in the same manner as the racial hierarchy (Bharadwaj, 2007). Therefore, this study used feminist literary ideas of Elaine Showalter (1985) to identify and expose gender inequalities through a close examination of the selected Kipsigis songs. 
Showalter's social and cultural criticism from a literary perspective made her ideas best suited for this study.

\section{LITERATURE REVIEW}

Contesting patriarchy means using available mental resources to produce various tools which can effectively counter the effects of patriarchy. Art is one such a tool. From the selected songs, it has been established that the following ways can be used to contest patriarch in the Kipsigis community of Kenya's South Rift region. The following sections look into three specific strategies:

\section{Use of Social Relationships and Popular Literature}

In his study, Kabaji (2005) considered the Maragoli folklore as a site for contesting patriarchal social structures, relationships, identities and ideology. He considered the performers, mostly women, as active agents who struggle for space in the patriarchal society. Drawing from the discourse of "othering", Kabaji argued that the condition of otherness enables African women to stand up and criticize the norms, values, and practices that the dominant culture (patriarchy) imposes on everyone, including those who live in the periphery. While Kabaji studied Maragoli folklore as a site for contesting patriarchal social structures, relationships, identities and ideology, this study focused on the Kipsigis songs as a site for women to contest patriarchal oppression by men.

\section{Contesting the Male Literary Voice}

Stratton (1994) looked at the "Mother Africa Trope" in African male literature and the subsequent romanticization of African womanhood, which masks subordination and the perpetuation of patriarchal socio-political order. In this case, Stratton argued that this trope goes against the interests of African women because it portrays them as being subordinate to the African menfolk. This, according to Stratton, perpetuates the oppression of women. She argued that women roles should be integrated with those of men, and vice versa, to subvert male dominance. While Stratton analyzed prose fiction, this study sought to use of Kipsigis songs to fight against the patriarch.

\section{THEORETICAL FRAMEWORK}

Interpretation and analysis of the selected songs for this study were theory-based. Elaine Showalter's feminist literary ideas were handy in the explication and analysis of texts.

\section{Feminist Literary Criticism}

Barry (2002) wrote that contemporary feminist literary criticism is the product of the 'women's movement' of the 1960s. He quotes Toril Moi's explanation of the distinction among 'feminist', 'female', and 'feminine' thus, "The first is a 'political position', the second a matter of biology and the third 'a set of culturally determined characteristics" (p. 85). Barry then lists the following as what feminist critics do:

1) Rethink the canon, aiming at the rediscovery of texts written by women.

2) Revalue women's experience.

3) Examine representations of women in literature by men and women.

4) Challenge representations of women as 'Other', as 'lack', as part of 'nature'.

5) Examine power relations which obtain in texts and in life, with a view to breaking them down, seeing reading as a political act, and showing the extent of patriarchy.

6) Recognize the role of language in making what is social and constructed seem transparent and 'natural'.

7) Raise the question of whether men and women are 'essentially' different because of biology, or are socially constructed as different.

8) Explore the question of whether there is a female language, an L'ecriture feminine, and whether this is also available to men.

9) 'Re-read' psychoanalysis to further explore the issue of female and male identity.

10) Question the popular notion of the death of the author, asking whether there are only 
'subject positions ... constructed in discourse', or whether, on the contrary, the experience (e.g. of a black or lesbian writer) is central.

11) Make clear the ideological base of supposedly 'neutral' or 'mainstream' literary interpretations (Barry, 2002, p. 92).

To the above list, Elaine Shawalter (2001) added her own views thus: the use of the term gynocritics to refer to women as producers of art that serves feminist agendas. This addition is useful since the proposed study examines the art produced by women and how these women artists deliberately strife to contest patriarchy in their art. Second, Showalter advocates for an approach to feminism from a cultural perspective. She argued that art could help to uncover and dismantle certain aspects of culture that support the status quo of women oppression.

In Toward a Feminist Poetics, Showalter (1979) stated thus:

In contrast to [an] angry or loving fixation on male literature, the program of gynocritics is to construct a female framework for the analysis of women's literature, to develop new models based on the study of female experience, rather than to adapt male models and theories. Gynocritics begins at the point when we free ourselves from the linear absolutes of male literary history, stop trying to fit women between the lines of the male tradition, and focus instead on the newly visible world of female culture (p. 131).

The above views show that the aim of feminist literary criticism is not to adopt male models and theories on gender differences but to understand women's artworks in relation to their unique female experiences. In the same way, the present study examined how Diana Musila and Babra Chepkoech, in their songs, define aspects of patriarchy, identify strategies that women use to contest patriarchy and deploy literary stylistics to contest patriarchy in their music.

Subordinating Showalter's views are Mama and Abbas (2015) whose ideas on feminism in Africa are tied to the Pan-Africanist struggle. This struggle is multi-layered since it seeks the liberation of both men and women from different forms of economic, political or ideological, cultural and social oppression. According to these authors, in many ways, patriarchy and colonial oppression have gone hand in hand in Africa. Therefore, they argue, female liberation is also an anti-colonial agenda on the continent. It is in this context that "Liberal and neoliberal women seek representation through entry into the existing structures of power and leadership. Others apply critical analysis to demystify the patriarchal structures and cultures which have often failed women" (p. 4). These two arguments by Mama and Abbas provide evidence of the conscious struggle against oppression, especially patriarchal oppression in Africa. Therefore, the present study treats the Kipsigis musicians as part of this conscious struggle as it employs Showalter's views to interpret the selected texts.

\section{Use of Popular Songs}

Popular literature is that literature which appeals to a large group of people. A song is a form of popular literature because it appeals to a large group of people. Since there are many genres of songs, all age groups of people will often find themselves listening to songs. Harris (2018) argues that popular arts are much more than constellations of social, political, and economic relationships; they are expressive acts. He further states that their most important attribute is the power to communicate which is eloquently testified to by the frequency with which they are repressed. Harris' views gave this study the basis for understanding how the Kipsigis songs (which are equally popular throughout the linguistic group), as literary texts, constitute spaces for contesting patriarchal oppression.

Similarly, Nyairo and Ogude (2005) in their research looked at Kenya's Gidi Gidi Maji Maji's popular song "Unbwogable", a song which became popular throughout the country. According to Nyairo and Ogude, the song was used by Kenyan opposition politicians in their campaigns during the 2002 general elections. According to them, the song was used to communicate political ideals to the target audience, which in this case were the voters. With the help of this popular song, the politicians 
were able to win the general elections since the communicative effect of the particular song was strong and powerful. Nyairo and Ogude's study attests to the power of popular songs to construct and alter realities. Like Nyairo and Ogude's 'Unbwogable' on its part, this study explored popular Kipsigis songs to establish how women are depicted in their struggle against patriarchy.

\section{METHODOLOGY}

This study adopted a qualitative research design which involved interpretation, analysis and description of data. The qualitative research design was useful when collecting information on social issues such as is the case in this study. Primary data was collected by closely listening to and watching selected popular songs stored on compact disks. Those songs that had content related to the topic of this study were selected for interpretation and analysis. Secondary material included academic materials: magazines, theses, published journal articles that were relevant to the stated problem.

This study purposively sampled ten popular Kipsigis songs by two Kipsigis artists, namely Diana Chemutai Chelele and Babra Chepkoech. The selected songs were discovered in the process of listening to popular Kipsigis songs, thus making this researcher obtain the information appropriate to the study objectives. Songs which did not contain the themes and styles relevant to this study were ignored. Both of the musicians were chosen because they had produced numerous songs which provided a huge pool from which this researcher obtained the target population for this study. The selected songs constituted $10 \%$ of the two artists' total oeuvre of the songs listened to.

The collection of primary data began with a cursory listening to the songs by the two selected singers which was followed by a close reading of the texts, namely the song's lyrics. The researcher then watched and (re)listened to audio-recorded forms of the songs to identify elements of performance and production that were relevant to the research objectives. Then, the researcher examined the overall composition of the songs in terms of accompaniments, structure of performance and sound to identify different features of patriarchy and stylistic engagements used by the singers.
The researcher also reviewed library materials like academic articles, books, journals and previous theses and projects to gather secondary data. Thereafter, the researcher analysed the data thematically, and then interpreted and discussed the findings based on the research objectives, contribution to existing knowledge and the theoretical framework adopted.

Once all the data had been collected, it was arranged, analysed, interpreted and discussed in relation to existing literature. The research employed an in-depth analysis of the song-texts to critically examine their use as space for contesting patriarchal oppression. According to Lindolf and Taylor (2002), qualitative researchers seek to preserve and analyse the situated form, content and experience of social action, rather than subject it to mathematical or other formal transformations. This study thus analysed content derived from selected songs.

\section{STRATEGIES USED BY WOMEN TO FIGHT PATRIARCHY}

\section{Economic Empowerment of Women}

Women in the Kipsigis community seem to have come to terms with the fact that they need to be empowered economically so that they can survive in a highly patriarchal culture. Chelele has been able to describe the levels of deprivation and disparateness in this society which favour men at the expense of women. In "Lagochu", the vulnerability of women has emerged prominently. Women thus must emancipate themselves from the chains of oppression, lest they remain permanently captive to the retrogressive aspects of patriarchy. She sings:

\section{I wish I would become young again \\ I will not get married but choose to be independent \\ Because if I had a job, my husband would respect me \\ But because I do not have, he despises me. \\ If it was possible to become young again \\ I will go to stay alone in a rental house and...}

This song aptly captures the extent to which women are oppressed. The singer wishes she were able to turn back the hands of time, so she refrains from 
ever getting married. She too wishes she had a job, probable referring to a white-collar job. She insists that she would then live in a rental house. It is not clear why she would prefer to rent a house rather than build her own. This researcher read this as the singer's resignation to the reality in the Kipsigis culture where men rarely allow their daughters to inherit land. She thus speculates that she would rent a house for herself rather than own one.

On her part, Diana Chemutai's female voice in the song "Bunyot" sings:

Let me move my business away from here; I may end up dying here - I will not give up

My money has made me suffer; I don't enjoy it - my pocket

He (husband) has not even paid my dowry, but despises my parents - he has not given my parents even a cat

This is a clear indication that the songwriter is using the structures in the song to promote emancipation of women from oppression and deprivation, by advising them to seek for more education, independence, jobs and social mobility. The two singers thus address the same issue prescribing what would help women stand on their own two feet: economic emancipation. This is what Showalter's aspiration: that art might be used to contest culturally undesirable traits.

\section{Persuasion}

The selected songs seem to suggest that the feminine power of persuasion has been grossly underestimated and misrepresented. Even women are able to exert themselves through persuasion by wielding tremendous power through silence; patriarchal cultures tend to overlook this. Kipsigis songwriters use persuasion as a tool to fight the patriarchal society. Through her song "Josi Josi," Barbra Chepkoech's female voice persuades society to sympathize with her by exposing her husband's stinginess, irresponsibility, and conceit:

Josi when are you going to buy me slippers?

I have been patient since Saturday

And slippers is only fifty shillings

I asked, and you replied that slippers are as expensive as buying a car

Of what use is your money Josi?

Only alcohol, women,

Smoking and drinking again and again

When I ask you for money you don't give me,

Yet you say you love me - Josi Josi

Why do you cheat that you love me?

You don't give me money for food

You don't give me money to buy things in the market
You don't give me money to buy clothes for children

Josi Josi, I will shout at you, I will shout at you

By exposing her husband in a song as an irresponsible, wasteful drunk, the female voice in the song attracts society's attention to the vices the man herein commits. Being a microcosm of this society's male folk, the man here is shamed. This would probably send a warning signal to the rest of the society which has the potential of turning things around. By not resorting to physical violence, the women ensure they survive in this oppressive culture as they work toward realizing a better tomorrow.

Besides refraining from direct confrontation with their husbands, women presented by the two songwriters seem to have perfected the art of pampering and spoiling their husbands as a strategy or technique to survive in the patriarchal society. The women regularly massage the men's egos by heaping praises on them. Chelele's song "Konon Elifut Joseph" shows the female voice refers to her husband as "Father of my children, father of Chepng'eno" as she requests him to give one thousand shillings. This flattery language is meant to help her achieve her survival objective. Women seem to have understood that if they pamper their men with praises, cajoling, coaxing, and use of flattering messages, they are able to win them and get what they want. At the same time, it has emerged from the songwriters that some women use sarcasm in their effort to woo their husbands, while men seem not to mind or are not aware that some praises may not be genuine as can be seen in the song "Josi Josi" by Chelele" where the female voice poses: "What exactly can you do for me to make me happy?" This indirect way of luring the 
man to soften his heart and probably do something for his wife, use of frequent discussions between the spouses, to name but a few, suggest to men that women are weak and deserve to be treated fairly. This is basically how women survive patriarchal oppression in the Kipsigis community. Art thus serves a feminist agenda here, echoing Showalter's theorization.

\section{Controlling and Nagging}

Nagging seems to be a tool which has been used extensively by women portrayed in the songs as a form of communication. Nagging here involves repetitious, pestering or continuously urging an individual for a favour, a request or to act on a certain piece of advice. In this case, what emerges from the songs is that women are repeatedly making requests, and the men repeatedly ignoring them. They end up in quarrelling each other because nagging appears to be more nauseating, though it does not ordinarily provoke men to outright violence. This is so because women want to avoid being more aggressive while continuing to repetitively request for what they want until the men comply with their requests. Sometimes, the woman gives up her attempt to persuade her husband to give in to her demands. This is aimed at avoiding nasty confrontations. Nagging also seems to be used by women as a way to control their husbands since women in Kipsigis culture are portrayed (see the song below) as weak, insecure and fearful; but here women seem to use nagging as a tool for fighting the patriarchal society in that the nagging is used to portray women (disguised) as fearful and weak thus creating an illusion of powerful and superior men. Power thus rotates here, creating a Foucaldian (1980) chain. The following song by Chelele "Konon Elifut Joseph" supports the foregoing argument:

I Chelele: Joseph assist me with one thousand shillings.

Joseph: I don't have.

Chelele: Joseph assist me with one thousand shillings.

Joseph: I have told you I don't have.

II Chelele: Why are you making me suffer Joseph?

Joseph: How am I making you suffer?

Chelele: Why are you making me suffer?

The wife here repetitively requests for money from her husband while the husband repeatedly responds in the negative. This trend is observed in Barbra Chepkoech's song "Jois Josi" below:

Josi Josi when are you going to buy me slippers?

I have been patient since Saturday

And slippers (a pair) is only fifty shillings

I asked and you replied that slippers is as expensive as buying a car

The husband here is adamant. He totally refuses to purge. This could be interpreted either as being irresponsible or being totally arrogant. He tends to believe that there is nothing the wife could do. It is upon this that the wife perhaps threatens to leave him as shown in Barbra's song "Mekwame":

I can't do this anymore wee
I am not coming back

My love, what have I wronged you?

You have begun trying me, what have I wronged you?

You have begun yelling at me, what have I wronged you?

Who is like you?

You have started tormenting me

You have started beating me

The songwriters above have presented a situation in which women in Kipsigis culture seem to have recognized that they hold a special place in society based on their roles as mothers of children which the community seems to value very much. The researcher argues that women also seem to play a pivotal role as the glue that connects in-laws and extended families besides keeping homes alive, the reason women can even threaten to leave their husbands (meaning that they shall go with the children) which is detrimental to the husband's clan 
as well the Kipsigis community as a whole. Barbra's song "Mekwame" presents a scenario in which the woman threatens to leave her husband, never to return to him. This return to her parents would break the marriage thus cause a huge loss to the man. This struggle to assert herself is what Showalter urges women to do: use art to front feminist agendas.

\section{Seeking Recognition}

Kipsigis women believe that it is paramount for their husbands to pay dowry and introduce them to their (husbands') parents in order to earn the respect that is associated with being legally recognized by both the families. Patriarchal societies seem to put a lot of effort into building bridges between in-laws. Women seem to have recognized this. Lines from Chelele's song "Ikanye" where the female voice demands to be formally introduced to her husband's family since she is tired of living in a rental house in various towns vindicate this way of thinking:

Take me to your home and show me to your parents $x 2$

We did not elope to stay in rental houses $x 2$

Also, women are seen mocking their husbands as failures since they have not paid dowry for them as seen in song "Bunyot" by Chelele whereby the singer says "Or you think my parents were paid camel as dowry." Similarly, some women are seen threatening to end the marriage if the husband will not abide by the women's demands to pay dowry. This is similarly seen in cases where fathers of daughters are seen looking forward to receiving dowry from their daughters' husbands as demonstrated in the song "Babainyun" by Chelele:

Maybe you want me to fight with your mother,

The cows I have seen, you want to refuse me

Unless you are not my daughter

In conclusion, it seems women felt/feel more secure in environments where their husbands have paid dowry for them, the dowry which seems to be a tool used to fight patriarchal culture as exhibited in the songs herein. This tool, when properly utilized, gives women a semblance of real power because they effectively have turned the tables on the men's clans by making the opposite of patriarchy reign: a case in which demands from women are met. This is the kind of art that Showalter advocates, an art that propagates a feminist agenda.

\section{Exposure and Unmasking the Society}

A woman in Kipsigis culture seems to have reached a point of no return and now they are left with no option but to expose their society's excesses against them. This is seen in the selected songs where the songwriters have dedicated themselves to expose the ills and difficulties facing women in the Kipsigis society. Songwriters seem to have deliberately decided to expose the rot of alcoholism, negligence of duty, and gender violence.

In the song "Bunyot" by Chelele, the singer says "I am tired trying to make this marriage work. It's like taking good care of the bull of Kibaiba." This is to indicate that men are seen as full of ego and they have abandoned their families while the women are forced to speak out against these injustices. Men seem to use deprivation as a tool to demand and manipulate women as can be seen in the song "Josi Josi" by Chelele, the singer sings:

When are you going to buy me slippers?

I have been patient since Saturday,

And slippers is only fifty shillings,

I asked and you replied that slippers areas expensive as buying a car

What is being presented here is a dysfunctional and disintegrating society. Women have refused to give up as can be seen in the song "Bunyot" by Chemutai:

I have tried putting it right with clay, it can't work,

I have tried using cement. It can't work, no use, I have tried using ugali; it can't work.

However, women seem to have reached a point that they are tired of trying to remain silent or being complicit in the evils they are subjected to. In the song "Bunyot" by Diana Chemutai, the singer cries:

I am tired of trying to make this marriage work It's like taking good care of the bull of Kibaibai, 


\section{It doesn't bear fruit but always makes me go back to square one}

The woman in character says she is tired of mending a broken pot, and from the song, she narrates all that she has been going through. Men are exposed as being very violent, negligent, and insecure. When one listens to the above song, they empathize with the woman and are left with no option but to support her decisions to break the silence and if possible, end the marriage. The songwriter is ready to unmask the pain and deeply hidden secrets of patriarchal structures which oppress women since it is only through talking that women can fight injustice.

In the song "Lagochu," Chelele laments:

Why are you hiding and accepting my husband to buy you meat?

Why don't you come home we drink sugarless tea together?

You think that man is wealthy,

You don't know that his land is like a tongue,

And has nothing in it.

The song shows that women are ready to expose their husbands for using falsehoods to lure them to be submissive and yet the men have left their families in abject poverty. The brave women seem ready to confront society's hypocrisy and expose it as can be seen in the song "Sugarless Tea".

\section{Minimizing Conflicts}

The analysed songs show that women in Kipsigis community show how these women combine a number of strategies to contest patriarchy on different fronts and platforms in society especially where it involves oppression, wife battering, domestic violence and general aggression against women. The sampled songs show that most women persuade their husbands to be responsible. Equally, the women try to be very submissive to minimize the frequency of abuse meted out to them by their husbands. In the song "Bunyot" by Diana Chemutai:

There is nothing you can do to recover a broken pot

It will break, it will burst

\section{I have tried putting it right with clay. It can't work \\ I have tried using cement. It can't work, no use I have tried using ugali. It can't work.}

This song portrays the singer as having despaired; she has come to a point she believes there is not much she can do to realize a change for the better in her husband. She mentions her attempts to mend a broken pot, something she has sadly realized is an impossibility. This researcher contends that although most women believe they can fight for their marriages, this song demonstrates that not all battles are going to be won. The tone of resignation in the female voice announces the fact that at times the best win is a loss. It is thus probable that this relationship could end up in dissolution, giving the woman the latitude to enjoy her freedom or lose that freedom later by trying out a new relationship.

\section{Summary of the Findings of this Study}

Women in Kipsigis culture seem to have come to terms with the fact that they need to be empowered economically and socially in order for them to operate successfully in the highly patriarchal Kipsigis culture. The songwriter has been able to describe the level of deprivation in this society which favours men at the expense of women. The most persistent theme that has emerged from the two songs is the vulnerability of women in the Kipsigis society. However, excerpts from the songs indicate that there is strong indication that the same vulnerable women have come to terms with this reality that the society will always oppress them if they do not strive to emancipate themselves from these chains of oppression. The songwriters have managed to show clearly that alcoholism is prevalent in the Kipsigis community; men spend the whole day in drinking dens oblivious of the problems that are faced by their families. The songs indicate that Kipsigis society seems to condone excessive drinking among men to the extent that it is a norm rather than an exception. Society seems to have accepted that men can waste all their money on alcohol and abdicate their domestic responsibilities.

The needs and interests of women are insufficiently reflected in the basic conditions under which they live, and that those conditions lack legitimacy 
because women are inadequately represented in the process of democratic self-determination. In this study, Showalter's literary feminist theory was used to help this researcher interpret how the condition of women in the Kipsigis society is in the transition from patriarchy to freedom. Specifically, the study used the theory to describe the existing tendencies of patriarchy in the Kipsigis society as depicted in the selected songs. Second, the theory helped this researcher to describe how patriarchal tendencies are being shaken at the foundation by the women's (and men to some extent) struggles against patriarchy in different cultural set-ups.

Analyses of songs by Barbra Chepkoech Bunyot portray females as being dependent on the whims of men for their survival. This is illustrated by the situation in which a woman has to wait patiently for a gift of slippers which only costs fifty shillings. The woman in the song pleads for men's understanding of her predicament. In most songs done by Diana Chemutai Musila and Barbra Chepkoech, it can be deduced that the society depicts or portrays man as a provider supposed to be depended upon by the women. This apparent elevation of men makes them feel superior since they occupy a higher position in the society, they use their economic advantage to hoodwink and control women.

In some of the songs done by both the selected artists, it can be deduced that the singers depict women as having the capacity to rebel against patriarchy by either fighting for their rightful place in marriage or by electing to leave toxic marriages and lead their own independent lives.

\section{CONCLUSIONS}

From the findings of this study, it has emerged that songs move beyond being a medium of entertainment to being instruments for transmission of culture and tools for exposing patriarchal oppression. In this case, Diana Chemutai Musila and Babra Chepkoech use songs to expose patriarchal structures in Kipsigis culture, give voice to disadvantaged females and inculcate survival strategies in them in their attempt to contest patriarchy. Analysis of the two artists' songs reveals that songs are a perfect medium of passing information and acting as a bridge to teach cultural practices and norms. Through the songs, the audience is able to learn something about the Kipsigis culture in terms of norms, taboos, spirituality, rituals, beliefs and perception of reality. Through the songs, the listeners get an opportunity to understand the intricacies and details of patriarchal societies. In the case of the two singers here, the main theme that emerges from patriarchal culture is its tolerance of violence against women whereby domestic violence ensures women face the real danger of losing status, incurring health problems and economic deprivation whereas men are allowed to be irresponsible, alcoholic and promiscuous.

The songwriters are acting as a bridge to unmask the suffering of women under patriarchal set-ups. What becomes clear is that gender violence is accepted as a way of life and as a tool to subjugate women, thus prompting them to unquestioningly obey men. The songs are able to expose the highhandedness and hypocrisy of men. The selected songs reveal glaring consistencies associated with patriarchal societies: women are almost always patronized, even by men who clearly fall into the category of imbeciles. In a way, the two songwriters have acted as freedom fighters, providing the downtrodden (mostly women) with a means to express themselves. They also challenge the society to change and adopt new ways of living which discourage gender violence. The songwriters advocate independent-mindedness of women and a need for their self-sufficiency which would perhaps ensure they are not dependent on the goodwill and the mercies of men. The artists equally advise women to go back to school and obtain an education that will give them the power to better their lives and their society at large. The selected songs also function as a tool for women and society to vent their anger, frustration, hurt and disappointment. Additionally, the songwriters have attempted to expose the hypocrisy of the society towards gender-based violence. Through the songs, the listener is able to establish the level of vulnerability of women in a patriarchal society. Another thing that emerged from the selected songs is that the songwriters have utilized their creativity for communicating patriarchal tolerance of violence against women as well coupled with the advancement of socio-economic isolation of 
women. Women deprivation thus emerges as a critical aspect of patriarchal societies.

\section{RECOMMENDATIONS}

Based on the findings of this study, the following recommendations were made: popular songs, in general, are used not only for entertainment but also to address issues of great concern for society. In the same fashion, Kipsigis songs serve to entertain and educate people on issues affecting the community. These issues include but are not limited to women's issues. There is need for composers therefore to develop music that portrays both positive and negative aspects of the lives of both men and women after all both genders live in real communities where life is not a bed of roses.

Due to the prevalence of patriarchy, the pursuit of gender equality became known as a women's issue, and, true to that fact, women have primarily been at the forefront of advancing the feminist agenda. However, it is important to note that gender parity is good for both men and women, and, as such, even men can join, and have indeed joined, the struggle for equality of genders. Though the selected songs did not yet point to that equality, this researcher still hopes that it is probable as years go by. With this in mind, it would be interesting for literary critics to conduct a study that sets out to establish the trajectory gender conflicts in literary texts (such as Kipsigis songs) are likely to take in patriarchal communities such as the Kipsigis of Kenya and what this portends for the future generations.

\section{REFERENCES}

Adeyeye, V. A., Ogundele, O., \& Hahn, N. D. (1988). A Study of Technology Adoption Among Alarola Women Group Farmers and Their Household Members in Ijaiye-Orile. Ibadan, Nigeria: IITA

Barry, P. (2002). Beginning theory: An introduction to literary and cultural theory (Second edition). LSU: LSU Press.

Bennett, A. (2005). Editorial: Popular Music and Leisure. Leisure Studies, 24(4), 333-342.
Bharadwaj, S. (2007). Women's Time. In Catherine B. and More J. (Eds.), The Feminist Reader (pp. 201-16.). London: Macmillan.

Chenorff, J.M. (1979). African rhythm and African sensibility. Chicago: Chicago University Press.

Dowd, H. (2007). Je tu nous: Towards a culture of difference, translated by A. Martin. New York: Routledge.

Foucault, M. (1980). "Two Lectures" Power/knowledge: selected interviews and other writings, 1972-1977. Colin Gordon. New York: Pantheon.

Harris, A. (2018). Introduction: African Street Literatures and the Global Publishing Go-Slow. English Studies in Africa, 61 (2), 1-8.

Kabaji, E. (2005). The construction of gender through the narrative process of the African folktale: A case study of the Maragoli folktale. Unpublished $\mathrm{PhD}$ thesis. University of South Africa.

Kazi, S. (1995). Rural women, poverty and development in Pakistan. Asia-Pacific Journal of Rural Development, 5(1), 78-92.

Kenig, W. M. (1996). Women's employment in Africa. Development Bulletin, 37, 27-29.

Kroska, G. (2007). Sex, gender and the body. New York: Oxford University Press.

Kumar, O. (1993). The history of doing: An illustrated account of movements for women's rights and feminism in India, 1800-1900. New Delhi: Kali for Women.

Lindolf, G. \& Taylor, H. (2002). Research methods in applied settings: An integrated approach to design and analysis (3rd Ed.). Mahwah, NJ: Lawrence Erlbaum Associates.

Mabawonku, H. (1988). African literature for children and young adults: An annotated bibliography of English language books 18731994. London: Greenwood Press.

Mama, A.\& Abbas, H. (2015). Editorial: Feminism and Pan-Africanism. Feminist Africa, 20, 1-6. 
Mary Anne, C. (1995). Disaggregating gender from sex and sexual orientation: The effeminate man in the law and feminist jurisprudence. Yale Law Journal, 1-105.

Moussa, M. (2015). Feminist perspectives on sex and gender. The Stanford Encyclopaedia of Philosophy.

Nyairo, J., \&Ogude, J. (2005). Popular music, popular politics: Unbwogable and the idioms of freedom in Kenyan popular music. African Affairs, 104(415), 225-249.

Olawaye, R. (1994). The theory of African literature. London and New York: Zed Books.

Rogers, H. (2013). Discourse analysis as theory and method. London: Sage.

Showalter, E. (1979). Towards a feminist poetics: Women's writing and writing about women. London: Croom Helm.

Showalter, E. (1985). The New Feminist Criticism: Essays on Women, Literature, and Theory. New York, Pantheon.

Stratton, F. (1994). Contemporary African literature and the politics of gender. London \& New York: Routledge.

Williams, J. (1998). The Good-Provider role: Its rise and fall. American Psychologist 36(1), 112. 